Levin, V., et al., 2020, Seismic anisotropy in southern Costa Rica confirms upper mantle flow from the Pacific to the Caribbean: Geology, v. 48, https://doi.org/10.1130/G47826.1

\title{
Seismic anisotropy in southern Costa Rica confirms upper mantle flow from the Pacific to the Caribbean.
}

Vadim Levin ${ }^{1}$, Stephen Elkington ${ }^{1}$, James Bourke ${ }^{1}$, Ivonne Arroyo ${ }^{2}$ and Lepolt Linkimer ${ }^{2}$

Department of Earth and Planetary Sciences, Rutgers University, Piscataway, New Jersey 08854, USA

Escuela Centroamericana de Geología y Red Sismológica Nacional (RSN: UCR-ICE) Apdo. 214-2060 San Pedro, Costa Rica

Shear Wave splitting methodology.

This brief synopsis is not meant to be a definitive guide to the methodology and is presented here to assist the readers in following the logic of our specific study. No attempt to provide comprehensive referencing of the method is made. Excellent reviews of the technique by Savage (1999) and Long and Silver (2009) are used to construct the narrative. Full details of our specific procedures are documented in Li et al., (2019).

Our data are horizontal records of ground motion in shear waves from large earthquakes at distances in excess of $\sim 87^{\circ}$ that have travelled as pressure waves through the liquid outer core. Consequently, their expected polarization at the bottom of the upper mantle is vertical. If encountering anisotropic material along their path through the upper mantle, these waves are expected to become birefringent (split), with orthogonal faster and slower components polarized along and normal to the symmetry axis of anisotropy. In the upper mantle we expect the symmetry axis to be fast relative to all other directions, controlled by the deformation systematics of the olivine crystals. Consequently, we present our results in terms of the fast polarization of the split wave and the "delay" - a time lag between the faster and the slower components that is proportional to the strength of anisotropy and to the length of the path within the anisotropic region (with full tradeoff).

Particle motion in the originally rectilinear split shear wave is expected to be the same for the faster and slower component. Thus we can determine the orientations of fast and slow polarizations by constructing trial time series rotated to all choices of orthogonal polarizations. A rotation that yields the highest similarity in pulse shapes is the answer. A time series crosscorrelation operation used to estimate similarity and to measure a time shift between two components gives the name to the Rotation-Correlation (RC) method (e.g. Ando et al., 1983). An alternative approach based on the expected vertical polarization of the split core-refracted shear wave seeks to find a rotation and time shift combination that will "correct" the effect of splitting, returning the particle motion to rectilinearity, as measured by the energy on the transverse component of the corrected waveform. A combination of rotation and time shift between components that produce the smallest reconstructed transverse component is the 
answer. Often described as a "minimization of transverse component" technqiue, this method was popularized by Silver and Chan (1988) and is referred to in our text as as SC.

Both above methods will return values of fast polarization and delay for any pair of orthogonal timeseries. The outcomes of two techniques will agree if anisotropy is simple (e.g. one volume with a horizontal axis of symmetry) and will likely diverge if multiple source of splitting and/or non-horizontal symmetry are present (cf. Long and Silver, 2009 for an extensive discussion). A special case of no splitting, referred to as NULL, is expected in two cases, either when there is no anisotropy along the path, or else when the ray is along the symmetry axis or normal to it. Clear-cut observations of NULLs (i.e. demonstrably rectilinear shear waves) are rare. A much more common occurrence is that of a NULL resulting from the data being too complex (due to noise or other effects) for the simple estimation scheme to handle. In this later case RC and SC methods behave differently - the former yields intuitively small delay times, and fast polarizations at $\sim 45^{\circ}$ to the ray direction (e.g Wüstefeld and Bockelman, 2007), while the latter produces largest delays possible in the settings of the search (typically 3-4 sec) and poorly constrained fast polarizations (e.g. Levin et al, 2007).

In our measurement procedure, we employ both methods simultaneously. The analyst makes a determination whether a measurement is a NULL. An exceptionally small ( $0.2 \mathrm{~s}$ or less) delay time from the RC method coupled with the exceptionally large delay time (reaching the maximum value assigned for grid search) from the SC method signifies a NULL. In essence, this is a statement of measurement failure.

To perform the analysis we employ the SplitLab environment (Wüstefeld et al., 2008) modified by Deng et al., (2017) to produce SI measurements.

Regional observations of shear wave splitting in SKS waves.

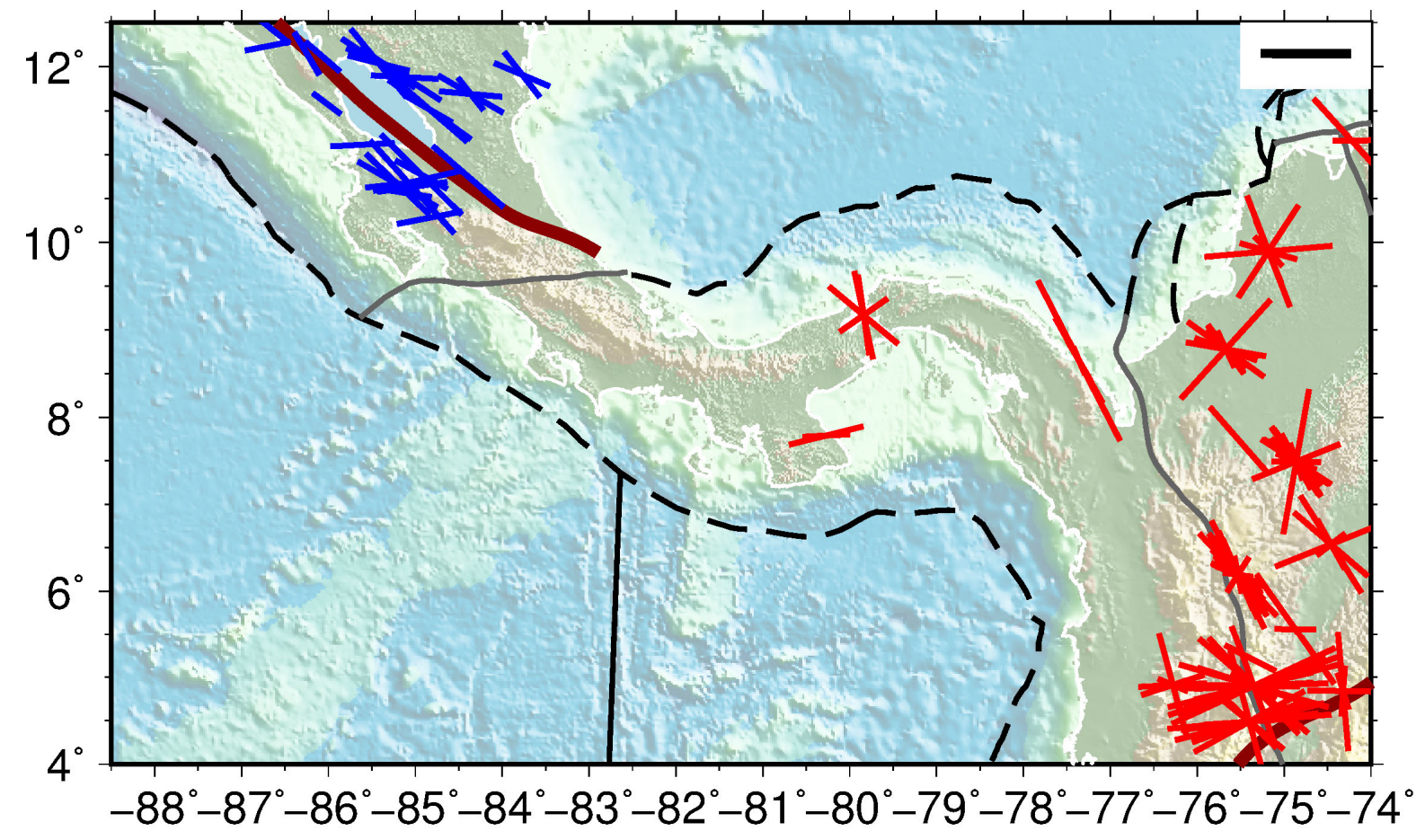


Figure S1. Published observations of shear wave splitting in the region. Data extracted from the database maintained by the IRIS Data Management Center (IRIS DMC, 2012). Studies contributing data to the plot: blue - Abt et al., (2010), red - Idárraga-García et al., (2016). Thick dark red line shows $160 \mathrm{~km}$ deep contour of the slab in the model of Hayes (2018).

Seismic data sources.

Our data come from two regional networks that operate broadband seismographs in southern Costa Rica. Red Sismologica Nacional (RSN) is a national network jointly operated by the University of Costa Rica (UCR) and the national power authority ICE. The network archives its data at IRIS DMC under the network code TC (Red Sismológica Nacional de Costa Rica, 2017). Another network is operated by Universidad National (UNA), with data from 2014 to 2018 presently available at IRIS DMC under the network code OV (Observatorio Vulcanológico y Sismológico de Costa Rica. 10.7914/SN/OV). All sites, their network affiliations, and date ranges for data used are listed in Table ST1.

\begin{tabular}{|l|l|l|l|l|l|l|l|}
\hline site & net & $\begin{array}{l}\text { \# data / } \\
\text { NULLs }\end{array}$ & data range m/yr & $\varphi_{a}$, deg & $\varphi_{f}$, deg & $\delta t_{a}, \mathrm{sec}$ & $\delta t_{f}, \mathrm{sec}$ \\
\hline ALCO & TC & $17 / 7$ & $12 / 2018-11 / 2019$ & $29 \pm 27$ & $31 \pm 27$ & $0.8 \pm 0.4$ & $0.5 \pm 0.3$ \\
\hline BATAN & OV & $39 / 7$ & $11 / 2014-5 / 2018$ & $28 \pm 22$ & $10 \pm 11$ & $0.9 \pm 0.3$ & $1.0 \pm 0.3$ \\
\hline CDM & OV & $80 / 45$ & $08 / 2014-5 / 2018$ & $56 \pm 38$ & $55 \pm 5$ & $0.9 \pm 0.4$ & $1.0 \pm 0.3$ \\
\hline PEZE & OV & $19 / 9$ & $09 / 2014-11 / 2016$ & $33 \pm 21$ & $55 \pm 14$ & $0.7 \pm 0.3$ & $0.7 \pm 0.4$ \\
\hline POTG & OV & $45 / 14$ & $10 / 2014-07 / 2017$ & $44 \pm 46$ & $43 \pm 9$ & $1.2 \pm 0.5$ & $1.1 \pm 0.3$ \\
\hline RGM0 & TC & $14 / 5$ & $01 / 2015-11 / 2017$ & $25 \pm 16$ & $-2 \pm 10$ & $1.4 \pm 0.5$ & $1.6 \pm 0.7$ \\
\hline SAJE & TC & $31 / 17$ & $08 / 2018-11 / 2019$ & $41 \pm 31$ & $58 \pm 4$ & $0.6 \pm 0.3$ & $1.1 \pm 0.3$ \\
\hline SRBA & OV & $39 / 27$ & $10 / 2014-04 / 2018$ & $46 \pm 41$ & $43 \pm 13$ & $1.1 \pm 0.4$ & $0.6 \pm 0.3$ \\
\hline VERF & TC & $20 / 1$ & $09 / 2018-09 / 2019$ & $17 \pm 24$ & $9 \pm 9$ & $0.9 \pm 0.3$ & $1.0 \pm 0.2$ \\
\hline
\end{tabular}

Table S1. Broadband seismic observatories used in the study, time ranges of data collection, number of data, fraction of NULL measurements, and values of averaged and best-fit shear wave fast polarization $\varphi$ and delay $\delta t$ (see main text for definitions). Error bounds for averaged values are computed using only non-NULL observations.

Figure S2. Shear wave splitting measurements and splitting intensity measurements for all sites used in the study. Proximate sites are grouped together to emphasize regional similarity in directional patterns of observed values. Sites form three natural groups: the Caribbean coast, Talamanca Mountains northwest, Talamanca Mountains southeast. Figure S3a shows site locations. 
(right) Diagrams of single-phase measurements: bars aligned with fast polarization (North is up, as in map view), scaled with delay, and referenced to the attributes of the ray for the corresponding phase. The stereonet diagram has coordinates of backazimuth (direction to the earthquake source, marked on the rim) and incidence angle $\left(0^{\circ}\right.$ to $18^{\circ}$, from the center to the rim, in $3^{\circ}$ increments). NULL measurements are shown as open circles. Red bars show RC value, blue bars show SC values.

(Left) Diagrams of splitting intensity (red circles with error bars), a sinusoid fit to those data (blue) and a sinusoid computed using average values of non-NULL splitting values from the RC technique (green).
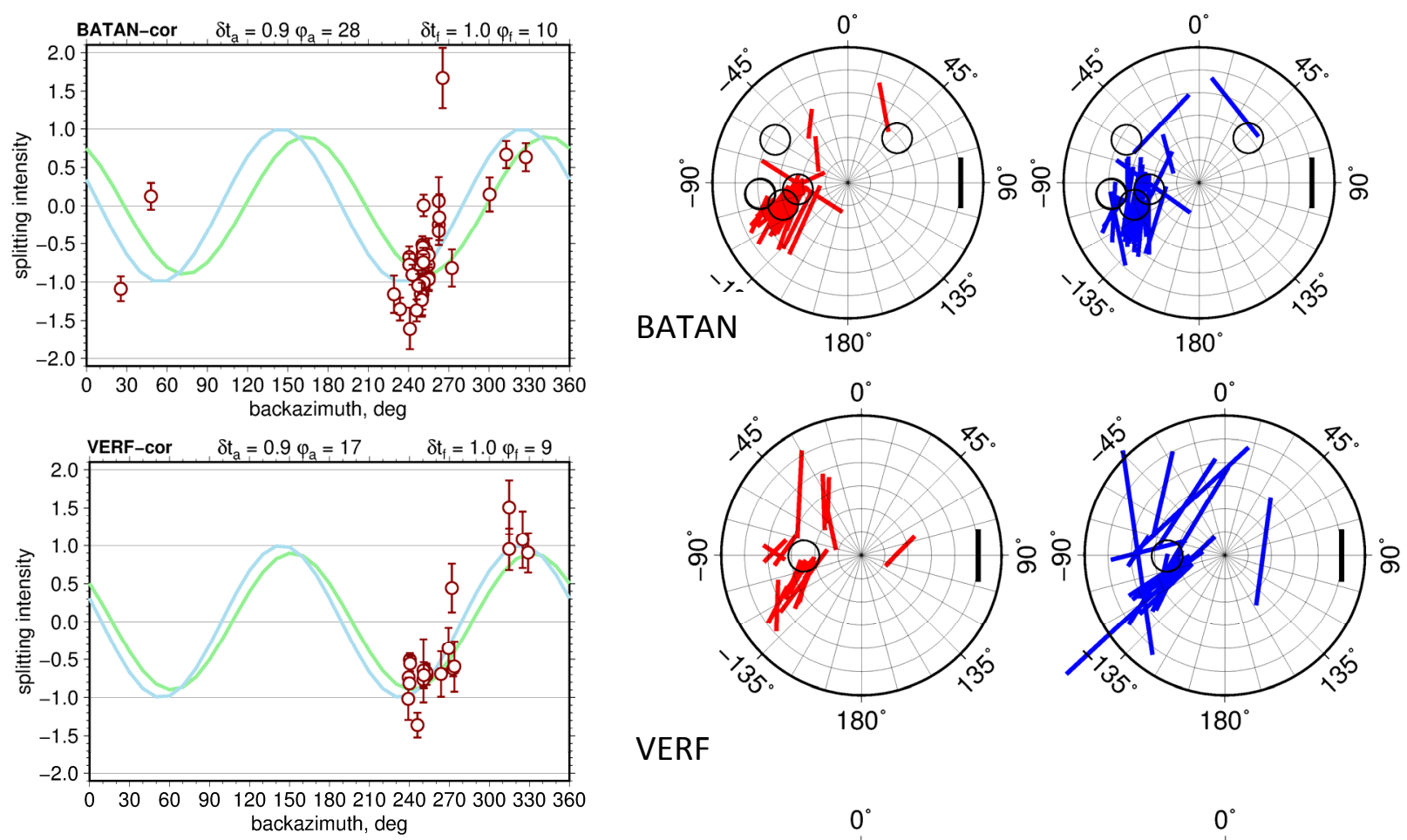

VERF
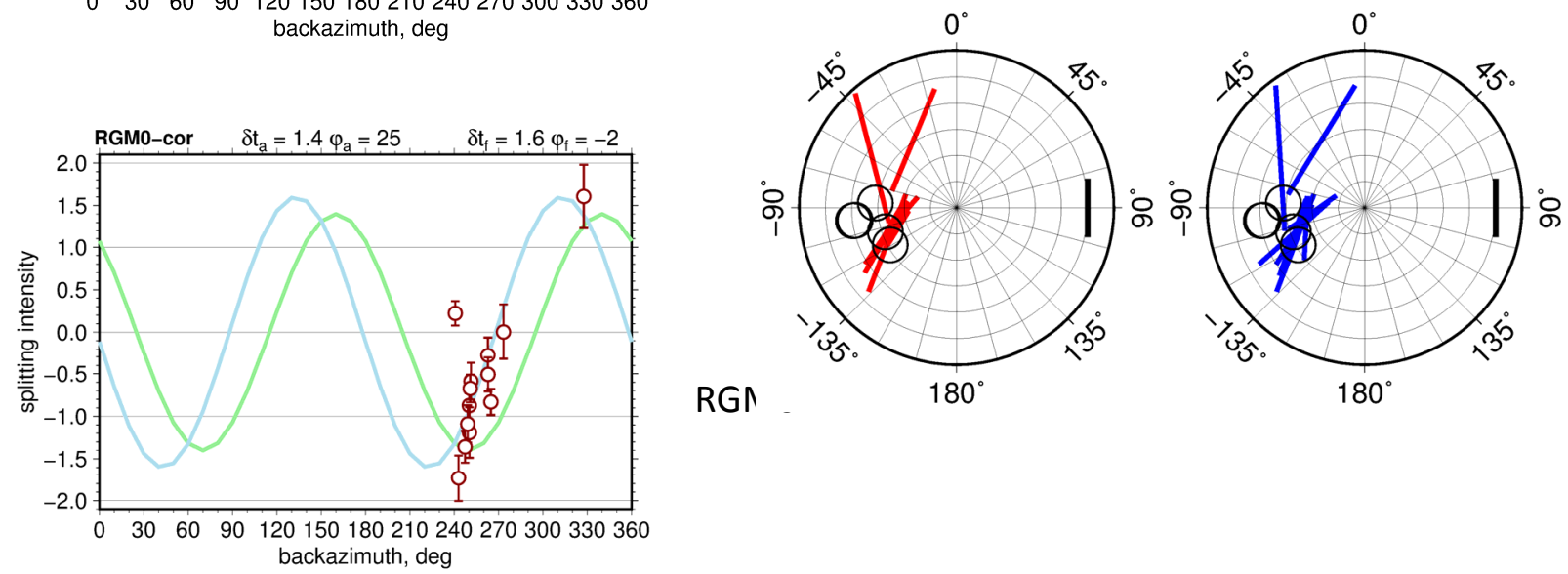

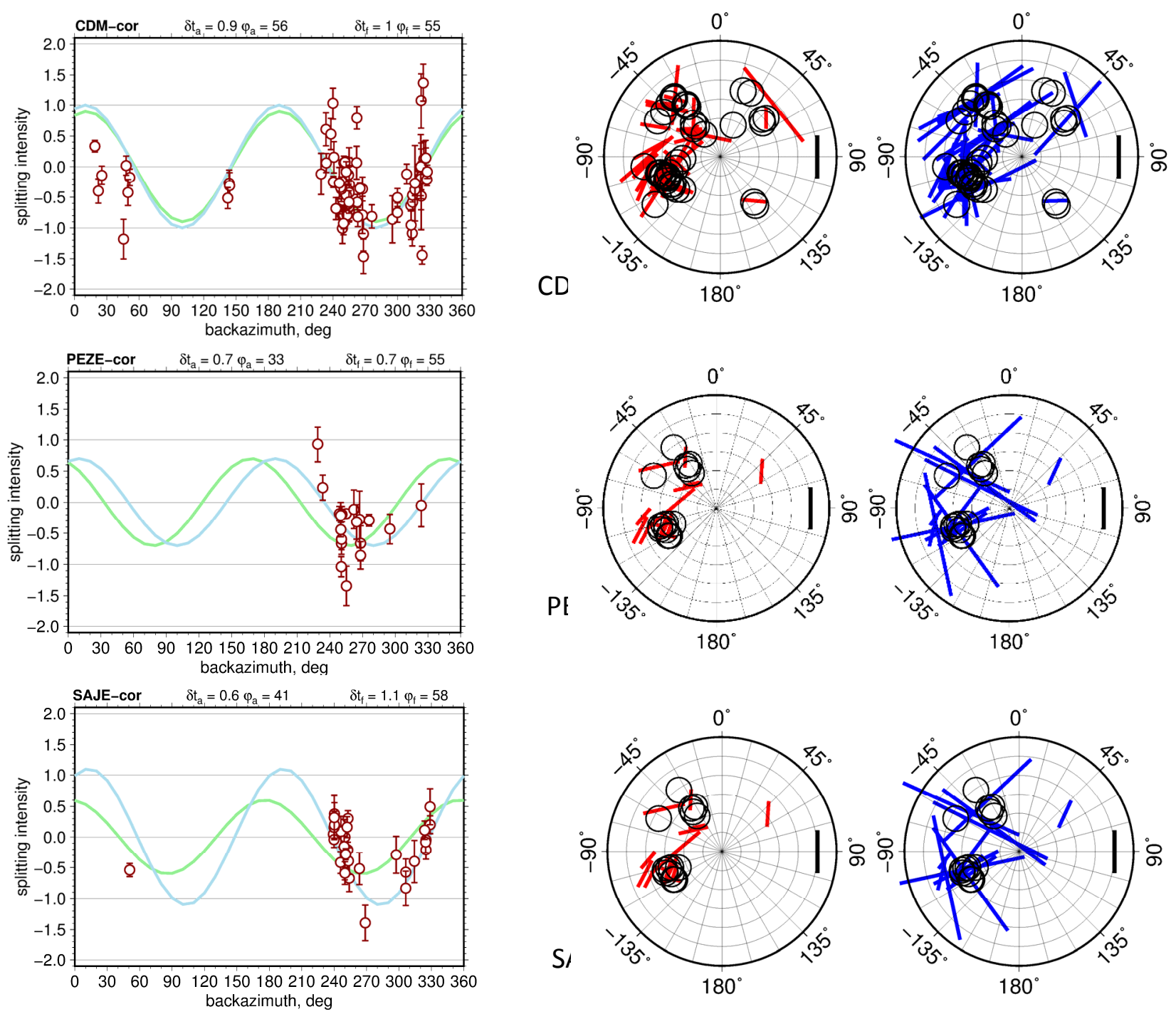

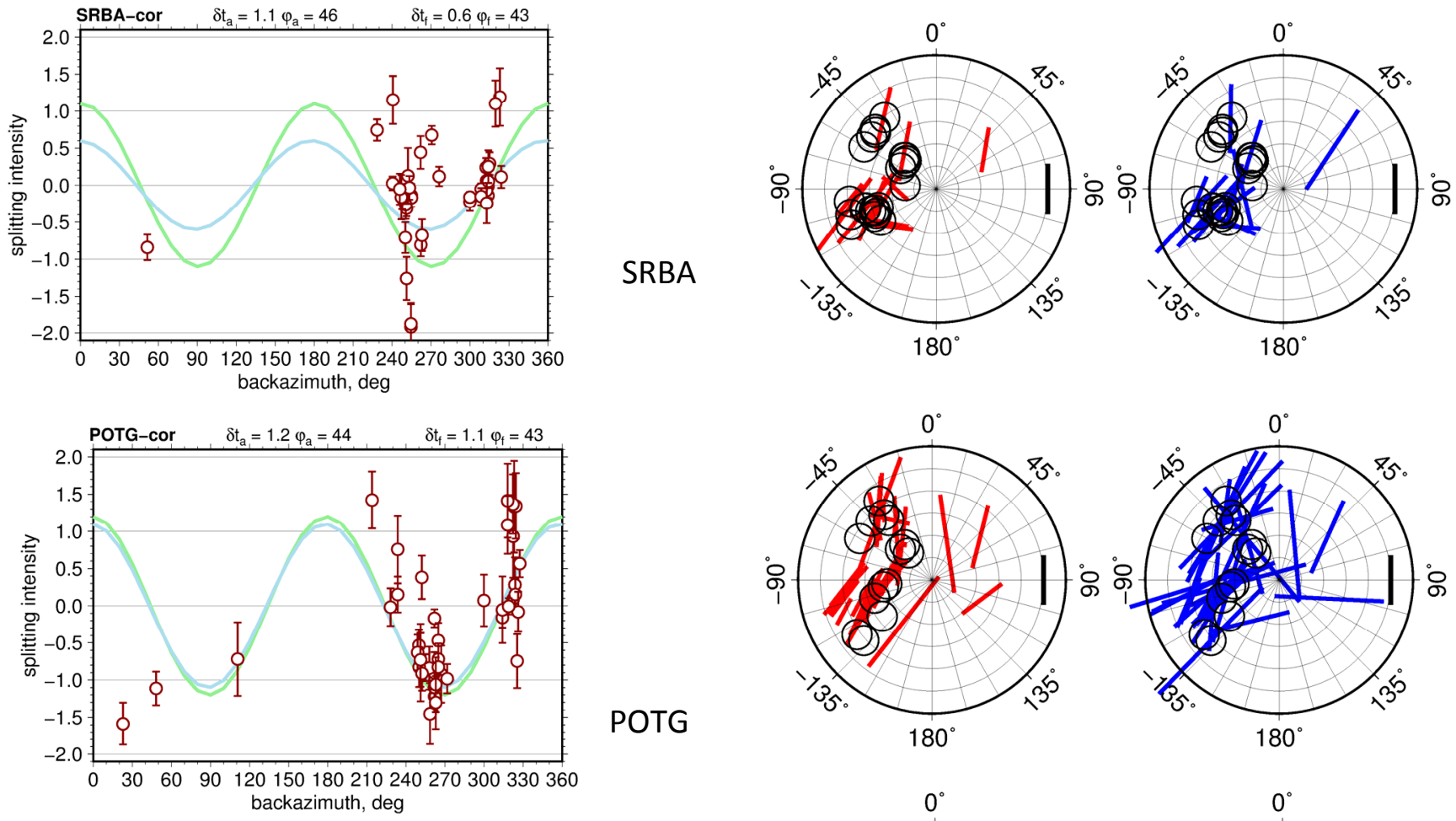

POTG
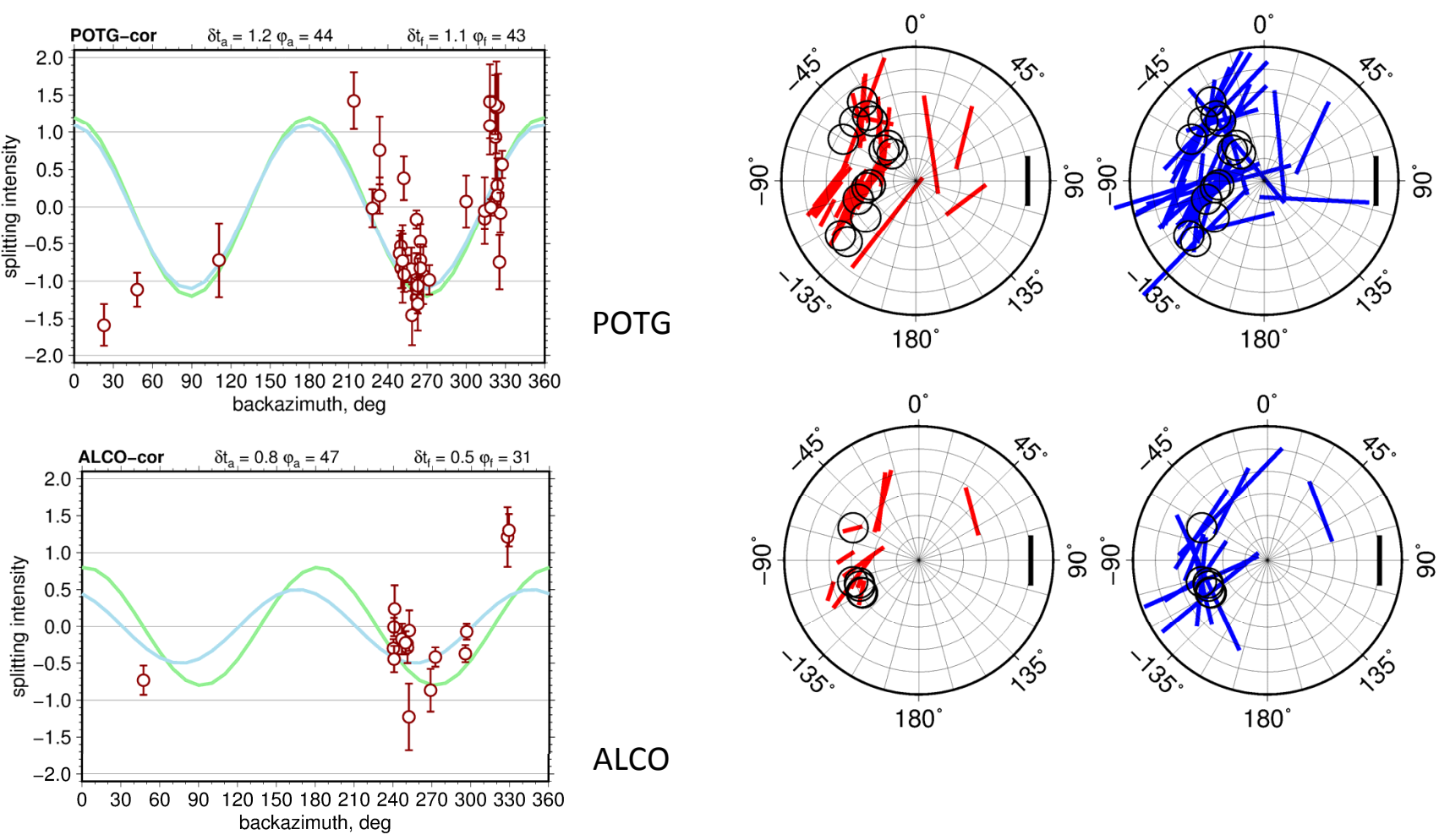

ALCO 

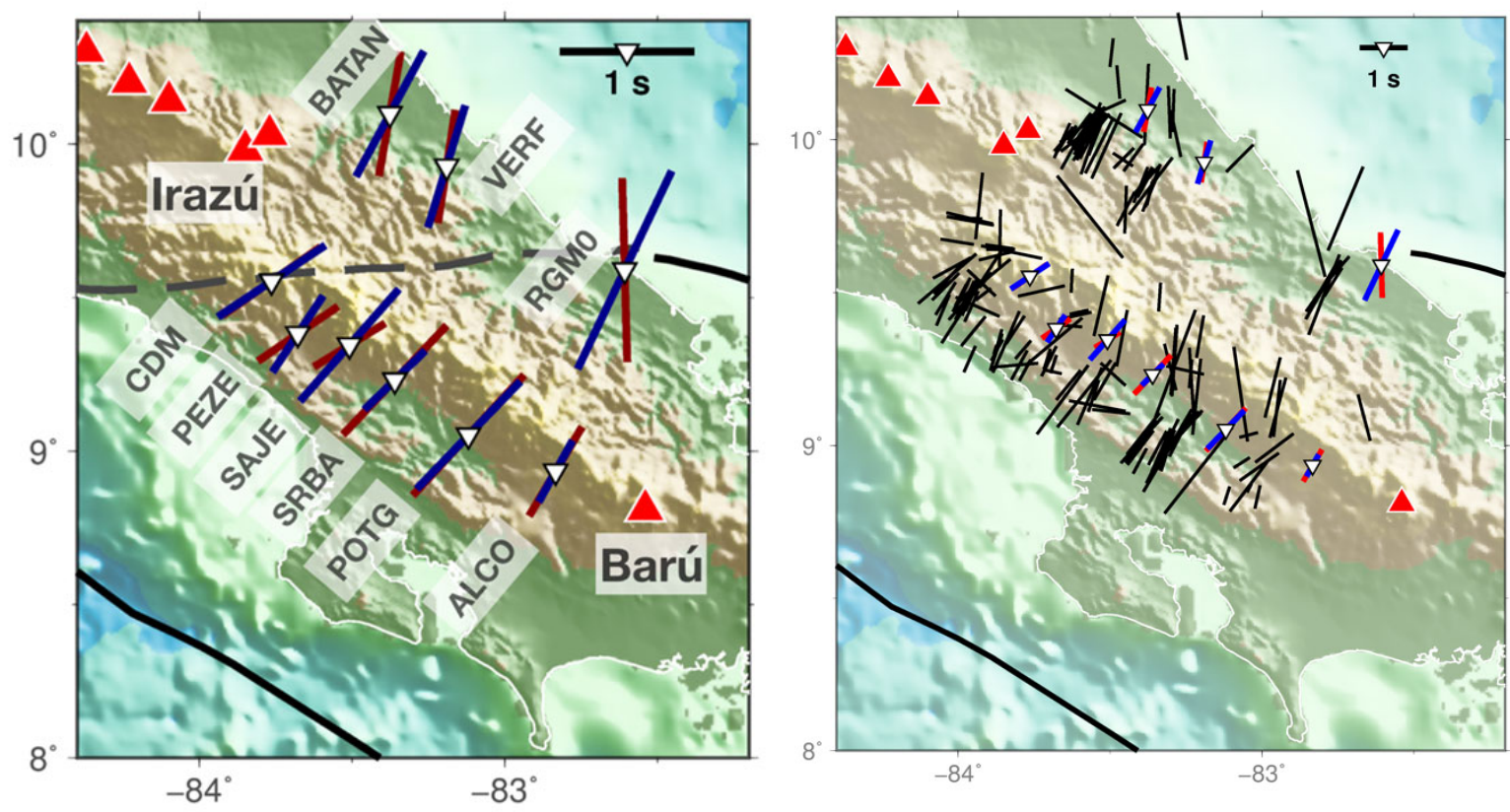

Figure S3. (left) Observations of averaged shear wave splitting for all locations, with labels. Average splitting parameters (blue) and predictions of these parameters from a fit to the splitting intensity values (red). Bars are aligned with fast directions and scaled with delay values. Two active volcanoes flanking the study region where volcanism is presently absent are labeled. Volcano locations are from the Global Volcanism Program (2013). (right) Individual measurements of shear wave splitting plotted at their respective rays' piercing points at $150 \mathrm{~km}$ depth (black bars) and averaged values (red and blue bars). Note the different scale for delays. 


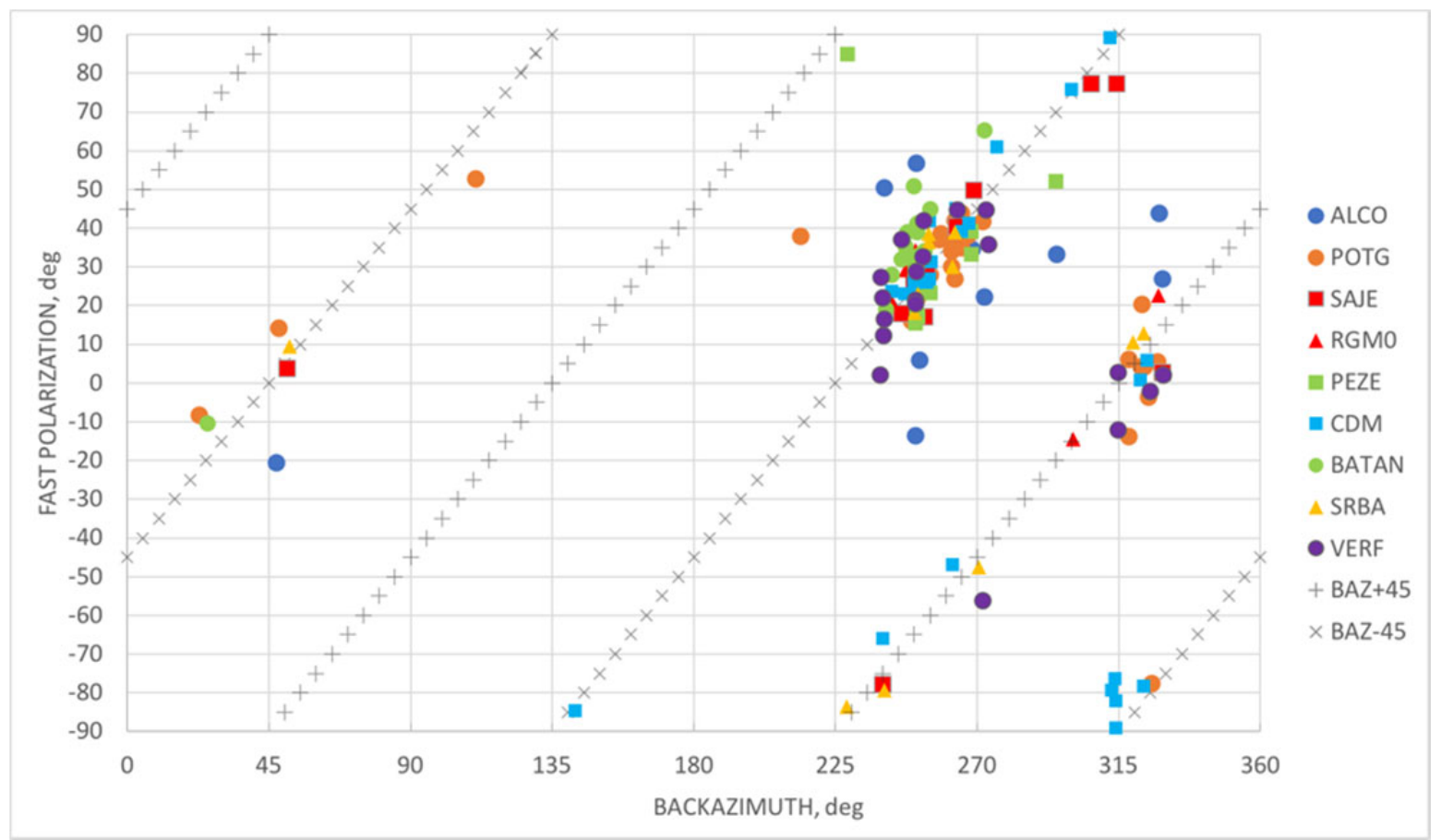

Figure S4. Fast polarization of non-NULL measurements obtained using Rotation-Correlation method (red bars in figure S3) plotted as a function of ray backazimuth.

\section{REFERENCES}

Abt, D.L., Fischer, K.M., Abers, G.A., Protti, M., Gonzalez, V. and Strauch, W., 2010, Constraints on upper mantle anisotropy surrounding the Cocos slab from SK(K)S splitting., J. Geophys. Res. 115, B06316, DOI: 10.1029/2009jb006710

Ando, M., Ishikawa, Y., and Yamazaki, F., 1983, Shear wave polarization anisotropy in the upper mantle beneath Honshu, Japan: Journal of Geophysical Research, v. 88, p. 5850-5864, https://doi.org/10.1029/JB088iB07p05850.

Deng, J., Long, M. D., Creasy, N., Wagner, L., Beck, S., Zandt, G., et al., 2017, Lowermost mantle anisotropy near the eastern edge of the Pacific LLSVP: Constraints from SKS-SKKS splitting intensity measurements. Geophysical Journal International, 210(2), 774-786.

https://doi.org/10.1093/gji/ggx190

Global Volcanism Program, 2013. Volcanoes of the World, v. 4.9 .0 (04 Jun 2020). Venzke, E (ed.). Smithsonian Institution. Downloaded 04 Jul 2020. DOI: 10.5479/si.GVP.VOTW4-2013. 
Idárraga-García, J., Kendall, J.M. and Vargas, C.A., 2016, Shear wave anisotropy in northwestern South America and its link to the Caribbean and Nazca subduction geodynamics, Geochem. Geophys. Geosyst., 17, 1-19, DOI: 10.1002/2016GC006323

IRIS DMC (2012), Data Services Products: SWS-DBs Shear-wave splitting databases, DOI: 10.17611/DP/SWS.1.

Levin. V., D. Okaya and J. Park, Cause and Effect: shear wave birefringence in wedge-shaped anisotropic regions. GJI, 168, pp. 275-286, 2007_doi: 10.1111/j.1365-246X.2006.03224.x_

Li, Y., Levin, V., Elkington, S., Hlavaty, J., 2019, Localized anisotropic domains beneath eastern North America. Geochemistry, Geophysics, Geosystems, 20, 5499-5521. https://doi. org/10.1029/2019GC008518

Long, Maureen D., and Paul G. Silver. 2009. "Shear Wave Splitting and Mantle Anisotropy: Measurements, Interpretations, and New Directions." Surveys in Geophysics 30: 407-61.

Red Sismológica Nacional de Costa Rica (2017). The Costa Rica National Seismological Network Catalog during 1975-2017. DOI: 10.15517/TC

Savage, M. (1999). Seismic anisotropy and mantle deformation: what have we learned from shear wave splitting? Reviews of Geophysics, 37(1), 65-106. doi:10.1029/98RG02075

Silver, P. G., \& Chan, W. W., 1988, Implications for continental structure and evolution from seismic anisotropy. Nature, 335(1), 34-39.

Observatorio Vulcanológico y Sismológico de Costa Rica, Universidad Nacional (1984): Observatorio Vulcanológico y Sismológico de Costa Rica. International Federation of Digital Seismograph Networks. Dataset/Seismic Network. DOI: 10.7914/SN/OV

Wüstefeld, Andreas, and Götz Bokelmann. 2007. Null Detection in Shear-Wave Splitting Measurements. Bulletin of the Seismological Society of America 97(4): 1204-11. https://doi.org/10.1785/0120060190

Wüstefeld, A., Bokelmann, G., Zaroli, C., \& Barruol, G., 2008, SplitLab: A shear-wave splitting environment in Matlab. Computers \& Geosciences, 34, 515-528. https://doi.org/10.1016/j.cageo.2007.08.002 